\title{
Smart cities in China: growth driver in the post pandemic world
}

\author{
Marina Reshetnikova ${ }^{1 *}$, Galina Vasilieva $^{1}$, \\ ${ }^{1}$ RUDN University, Faculty of Economics, Miklukho-Maklaya, 6, 117198 Moscow, Russian \\ Federation
}

\begin{abstract}
Research background: In recent decades, a global trend towards the introduction of IoT technologies, artificial intelligence, blockchain, and many others into the field of urban management to create a single digital ecosystem has become increasingly noticeable. The urgency of this problem also manifested itself during the COVID-19 pandemic, and many components of the smart city made it possible to control and contain the spread of the infection. All these factors testify that in current conditions, the digitalization of cities is simply inevitable. In this regard, the number of smart cities continues to increase worldwide, and their development models are constantly improving under the influence of a considerable number of innovative solutions

Purpose of the article: Of particular interest are the Chinese successes in the rapid digitalization of the economy and society and the increase in the number of smart cities. The study aims to analyze and identify trends in the development of smart cities in China.

Methods: Since the concept of "smart city" is relatively modern and is in constant development, the authors have studied various articles and reports on this topic to identify different opinions about this topical problem. As part of the study, the authors carried out a visual clustering analysis of smart cities distribution in China.

Findings \& Value added: The authors were able to identify that the Chinese smart cities market has its own characteristic features, which allowed it to achieve such success. In more detail in this article, the authors focused on cluster development and highlighted the geographical pattern of smart cities distribution in China and their strengths and weaknesses in each area.
\end{abstract}

Keywords: smart city, China, cluster, digitalization, COVID-19

JEL Classification: O14; O18; R11; R12; H43

\footnotetext{
*Corresponding author: reshetnikova-ms@rudn.ru
} 


\section{Introduction}

Currently, the growth rate of the urban population continues to increase from year to year. In $2019,55.3 \%$ of the world's population lived in cities, and by 2050 it is expected to grow to $68 \%$ (UN, 2018). This, in turn, leads to testing cities for strength and necessitates their development and comprehensive optimization of urban infrastructure.

Innovation in all its forms has long been an integral part of our daily life. In recent decades, a global trend towards the introduction of IoT technologies, artificial intelligence (AI), blockchain, and many others into the field of urban management has become increasingly noticeable. The urgency of this problem also manifested itself during the COVID-19 pandemic, and many components of the smart city made it possible to control and contain the spread of the infection. All this testifies to the fact that in current conditions, the digitalization of cities is simply inevitable. Therefore, the number of smart cities continues to increase worldwide, and their development models are constantly improving under the influence of a vast number of innovative solutions.

However, it is not enough to know what a smart city is. It is much more critical to understand global trends in their development, analyze the experiences of different countries in this area, and predict this market's state. Of particular interest are the successes of China in the rapid digitalization of the economy and society, as well as the increase in the number of smart cities in this country. The study aims to analyze and identify trends in the development of smart cities in China.

\section{Methods and research background}

Since the very concept of a smart city is relatively modern and is in constant development, the authors have studied scientific articles, reports on this topic to highlight various opinions about this concept. Further, when analyzing the conjuncture of the world market of intelligent cities and the Chinese market, the authors collected statistical data that could characterize the current situation on the market and its development trends. Therefore, we used thematic reports from various analytical agencies such as International Data Corporation (IDC), PwC, and others as a statistical base. It is also worth noting that statistical data vary significantly in all the above reports, so we compared them and then generalized to identify common patterns and trends. Also, in this article, we have built a geographic map to visualize the distribution of smart cities in China.

Cities play a considerable role in all spheres of human life; they center on the concentration of human, economic, and industrial resources. This undoubtedly leads to a detrimental effect on the environment. People change natural landscapes, emit harmful substances into the atmosphere and water bodies, and violate the ecological balance (Trettin et al., 2019). At the end of the XX century, world communities began to think about the harm caused to the environment and how to deal with it. After that, in 1987, the UN International Commission on Environment and Development published the report "Our Common Future" (Brundtland and Khalid,1987). The concepts of sustainable development of human activity in harmony with nature were formulated for the first time.

All this gave impetus to the emergence of the concept of a smart city, but it began to develop only in the environmental direction since environmental protection issues became pronounced and required immediate intervention (Albino and Berardi, 2015). Therefore, all IT solutions of that time were so-called "green technologies" with a narrow scope. Some cities began to introduce various sensors into their infrastructure, which, for example, measured air pollution, traffic intensity, and the filling of garbage containers. Thanks to these innovations, it was possible to optimize and establish individual processes of urban life, but they did not form an automated and unified system of urban infrastructure. Therefore, such cities could not yet be called "smart," but over time, other pressing problems and tasks 
appeared, and the Internet of Things, AI, blockchain, Big Data developed, digital twins appeared, which led to the formation of a modern the concept of a smart city.

The development of the concept occurs in the following directions: urban environment urban planning, housing, and communal services (Trindade et al., 2017), digital mobility transport, information technology, and communications, tourism (Oliveira et al., 2020), urban economics - finance, industry, trade and services, innovation (Sun et al., 2016), safety and environment (Kumar, 2019), digital government - government activity, open government (Talari et al.,2017), human and social capital - culture, education, healthcare (Pacheco Rocha et al.,2019). Thus, we can conclude that the concept of a "smart city" seeks to ensure sustainable growth in citizens' quality of life, establish a favorable business climate, to the possibility of centralized, continuous, and most importantly, transparent management of the city. A "smart city" is a city, first, a city for a person, where all residents participate in its management with the help of AI, digital technologies, which have cross-cutting properties in all areas.

It should also be understood that all smart cities are divided into two groups. The first group includes cities that were once ordinary but went through the following stages of development: Smart City 1.0 - local IT implementation, Smart City 2.0 - primary digital infrastructure, Smart City 3.0 - unified digital infrastructure (Yun and Lee, 2019). The second group includes cities built from scratch immediately according to the standards of a smart city. However, such projects are not always successfully implemented since they require huge budgets and the rapid introduction of a single digital ecosystem. Such an unsuccessful example is the unfinished South Korean city of Songdo (Kuecker and Hartley, 2020).

So, from all the above, we can conclude that the concept of a smart city is an actual global trend that can bring significant changes to the structure of a city by creating a single digital ecosystem.

\section{Results}

The forecasted value of global costs in the field of smart cities in 2021 will be $\$ 124$ billion, compared with $\$ 104$ billion in 2019 (an increase of 18.9\%), and by 2023 expected to grow to $\$ 189.5$ billion (IDC,2020). Moreover, all these investments pay off in full, since the quality of life in such cities is increasing, the services provided to citizens are becoming more efficient. For better quality, for example, in healthcare or education, transport accessibility is also improving, and all city resources are used rationally.

If we consider the regional division, then more than $70 \%$ of world investments in this area are in the USA (25.9\%), Western Europe (24.7\%), and China (21.5\%) (IDC, 2019). Moreover, the priority areas for investments worldwide are energy, infrastructure projects, public safety, and intelligent transport.

Today, there are two world leaders in smart cities, namely China - 12 cities (including Hong Kong and Taipei), the United States - 10 cities.

China has become a global leader in innovative city initiatives, combining embedded sensors, instrumentation, CCTVs, and other monitoring technologies with big data processing and AI analysis to make it easier to manage its cities and public spaces. The country's leadership demonstrates enthusiasm in developing smart cities by launching a national strategy in this area and channeling public resources to promote their growth. China has nearly 800 pilot smart cities programs underway or planned, accounting for more than half of all smart cities in the world ( $\mathrm{Yu}$ and $\mathrm{Xu}, 2018$ ).

To understand how China achieved such success in this area, we need to trace how the concept has developed in this country. Thus, China's success is the result of a twenty-year policy of informatization of city management, which has constantly evolved following several factors, including the state of domestic and global development of technology, trends 
in this policy abroad, and, equally important, the role of technology in maintaining internal stability and social monitoring. From the mid-1990s to 2015, this concept in China went through 5 stages (Zhang et al.,2019).

The policy of cities digitalization, which began in the 1990s, is based on the initiatives of the National Bureau of Surveying and Mapping, which focused on the geographic information systems (GIS), a global positioning system (GPS), and Earth remote sensing (ERS). The concept of "information cities," which appeared in the mid-2000s, has already focused on the informatization of cities by digitalizing a wide range of public systems, such as municipal management systems and urban infrastructure, including their linkage with information technology and modernization of telecommunications infrastructure. The next stage of development - "smart cities," aimed to optimize and facilitate the flow of data between these state information systems through standardization and interoperability. The modern form of the concept of "new smart cities" is characterized by adopting newgeneration information technologies such as IoT, cloud computing, pervasive mobile networks, and big data systems to increase the level of intelligence and automation in urban planning and management.

We are witnessing a progressive and constantly improving Chinese policy in smart cities to establish functional and effective local governance and promote rapid urbanization and industrialization. Since 2009, some of China's smart city concept hallmarks have been the centralization of decision-making and the decentralization of their implementation, as well as a bottom-up approach, which has been quickly replaced by standardized top-down programs from the central government in a 12-year plan published in 2010. This allows us to conclude that this concept in China is developing according to the triple helix model (Reshetnikova, 2021). At the beginning of this plan in 2012, the Ministry of Housing and Urban-Rural Development (MOHURD) approved the first group of 90 pilot projects of smart cities on a cluster basis. Efforts in this area are only becoming more ambitious, and as of 2019, the number of such projects has reached almost 800 (Fig. 2.), including about 300 projects certified and sponsored by MOHURD (Song et al., 2021).

Such successes in smart cities are primarily due to significant public investment, so by 2019 , all pilot projects had already received more than $\$ 139.9$ billion on smart cities initiatives and by 2023 , this value is expected to reach $\$ 38.92$ billion (Wang et al., 2020).

With the growth of investments, the market volume for smart cities in China also grows. In 2018 its size was estimated at $\$ 30.4$ billion and is expected to grow to $\$ 59.9$ billion by 2023 (an annual growth rate of 14.5\%) (USCC, 2019). Moreover, with its growth, the market for smart cities solutions also develops. A significant role in the development and implementation of smart cities solutions in China was played by foreign and international giants, which we already talked about in the previous chapter, such as IBM, Cisco, Microsoft, and Bosch, but now, it is Chinese companies that dominate this market. (Table 1.)

Table 1. Chronology of cities informatization in China

\begin{tabular}{|l|l|}
\hline Key technologies & Key companies \\
\hline IoT, 5G & $\begin{array}{l}\text { Huawei, China Mobile, Inspur, China Unicom, Tencent, ZTE, } \\
\text { H3C, Sugon, Alibaba Cloud, Hikvision, Dahua }\end{array}$ \\
\hline Big data & $\begin{array}{l}\text { Neusoft, Tencent, Huawei, Inspur, Beiming Software, H3C, } \\
\text { Sugon, Taiji, Digital China, Alibaba Cloud }\end{array}$ \\
\hline Cloud computing & $\begin{array}{l}\text { Sugon, Alibaba Cloud, Tencent Cloud, Huawei, UCloud, China } \\
\text { Telecom, Amazon Web Services, Kingsoft, Microsoft Azure, } \\
\text { Baidu Cloud }\end{array}$ \\
\hline Artificial Intelligence & $\begin{array}{l}\text { Alibaba, Baidu, Tencent, iFlyTek, Huawei, SenseTime, Megvii, } \\
\text { Intellifusion, CloudWalk, Yitu, Hikvision, Dahua }\end{array}$ \\
\hline
\end{tabular}

Source: Compiled by the authors. Data collected from: USCC (2019). 
Let us dwell in more detail on the technologies of the IoT and mobile infrastructure because it is no secret that China is the world leader in the launch and implementation of $5 \mathrm{G}$ communications. So, in 2020, China carried out colossal work in this area, which allowed it to create the world's largest $5 \mathrm{G}$ network. At the end of the year, there were more than 780 stations, and by 2024 this figure is expected to reach 6.22 million (Fig. 1).

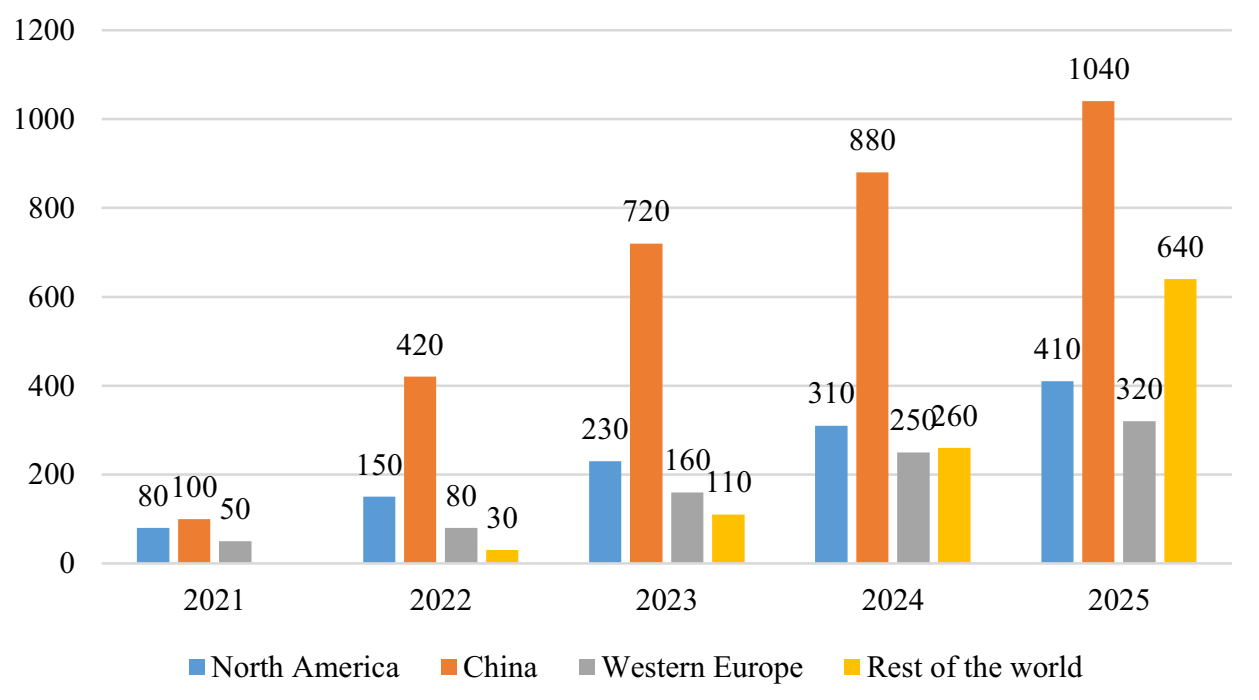

Figure 1. Projected 5G Connections Worldwide by Region from 2021 to 2025 (Millions)

Source: Compiled by the authors. Data collected from: Wang et al., (2021)

Such efforts of China in this direction are not accidental because it is on this generation of communication that most technologies and solutions of the smart city can work. So, in 2020 , there were more than 1.1 thousand projects in the country based on the use of $5 \mathrm{G}$ and the industrial Internet, and over 32 thousand base stations serving the industrial Internet (Wang et al.,2021). The authors also identified the main categories of technologies used in these projects, their specific components, and companies that exported these solutions worldwide.

Table 2. Review of identified exports of smart city technologies

\begin{tabular}{|c|c|c|}
\hline $\begin{array}{c}\text { Technology } \\
\text { category }\end{array}$ & Products & Companies involved \\
\hline $\begin{array}{c}\text { Video } \\
\text { surveillance }\end{array}$ & $\begin{array}{c}\text { IP cameras, video recorders, video } \\
\text { management systems, police } \\
\text { cameras, traffic surveillance } \\
\text { systems, face recognition, IR } \\
\text { cameras, license plate recognition. }\end{array}$ & $\begin{array}{c}\text { Huawei, Hikvision, Dahua, } \\
\text { Shenzhen ZNV, Megvii, } \\
\text { Kedacom, Cloudwalk, } \\
\text { Uniview, E-Hualu, Yitu }\end{array}$ \\
\hline $\begin{array}{c}\text { Network } \\
\text { infrastructure } \\
\text { Backbone networks, Wi-Fi, high- } \\
\text { speed networks, 3G, 4G, and 5G } \\
\text { infrastructure, LTE networks }\end{array}$ & $\begin{array}{c}\text { Huawei, ZTE, H3C } \\
\text { Cloud networks, data centers, } \\
\text { servers }\end{array}$ & $\begin{array}{c}\text { Huawei, Alibaba, Tencent, } \\
\text { Sugon, Inspur, Sangfor, } \\
\text { iSoftStone, ChinaSoft }\end{array}$ \\
\hline Fintech & $\begin{array}{c}\text { Mobile payment applications, } \\
\text { automated payment systems }\end{array}$ & $\begin{array}{c}\text { Huawei, Ping'an, Panda } \\
\text { Electronics }\end{array}$ \\
\hline \multicolumn{2}{|c}{}
\end{tabular}




\begin{tabular}{|c|c|c|}
\hline $\begin{array}{l}\text { Integrated } \\
\text { platforms }\end{array}$ & $\begin{array}{c}\text { Emergency response systems, "safe } \\
\text { city" solutions, unified city } \\
\text { operating platforms, command } \\
\text { centers, dispatch systems, call } \\
\text { centers }\end{array}$ & $\begin{array}{c}\text { Huawei, ZTE, Dahua, } \\
\text { Alibaba, Kedacom, Shenzhen } \\
\text { ZNV }\end{array}$ \\
\hline Energy & $\begin{array}{l}\text { Smart grid, smart meters, advanced } \\
\text { metering infrastructure (AMI) }\end{array}$ & Huawei, ZTE, CEIEC Electric \\
\hline $\begin{array}{l}\text { Municipal } \\
\text { services }\end{array}$ & $\begin{array}{l}\text { Smart parking, traffic guidance and } \\
\text { control systems, bus system, } \\
\text { intelligent streetlights, intelligent } \\
\text { waste management }\end{array}$ & $\begin{array}{c}\text { Huawei, Hikvision, Dahua, } \\
\text { Kedacom Gosuncn, E-Hualu, } \\
\text { Panda Electronics, Founder } \\
\text { International, Carsmart, } \\
\text { TelChina, Shenzhen ZNV, } \\
\text { iSoftStone } \\
\end{array}$ \\
\hline
\end{tabular}

Source: Compiled by the authors. Data collected from: IDC (2020), USCC (2019), PWCC (2020).

Thus, we observe that dozens of Chinese companies are involved in international projects, but the most prominent exporters are Hikvision and Huawei. We are also seeing that a wide range of countries is using Chinese smart cities technologies to solve internal problems of urban safety, transportation, and municipal services, and China, in turn, meets this strong demand (PWCC, 2020). In the 13th five-year plan of economic and social development, 19 clusters of smart cities were identified, which will account for about $80 \%$ of the entire economy of China. Within the framework of this work, we analyze five key clusters, which include 97 cities with a total population of 539 million people, an area of $986,000 \mathrm{~km} 2$, and a GDP of 38.277 million yuan. For clarity, we compiled a geographic map of data distribution from 5 clusters using mapping tool (Fig. 2).

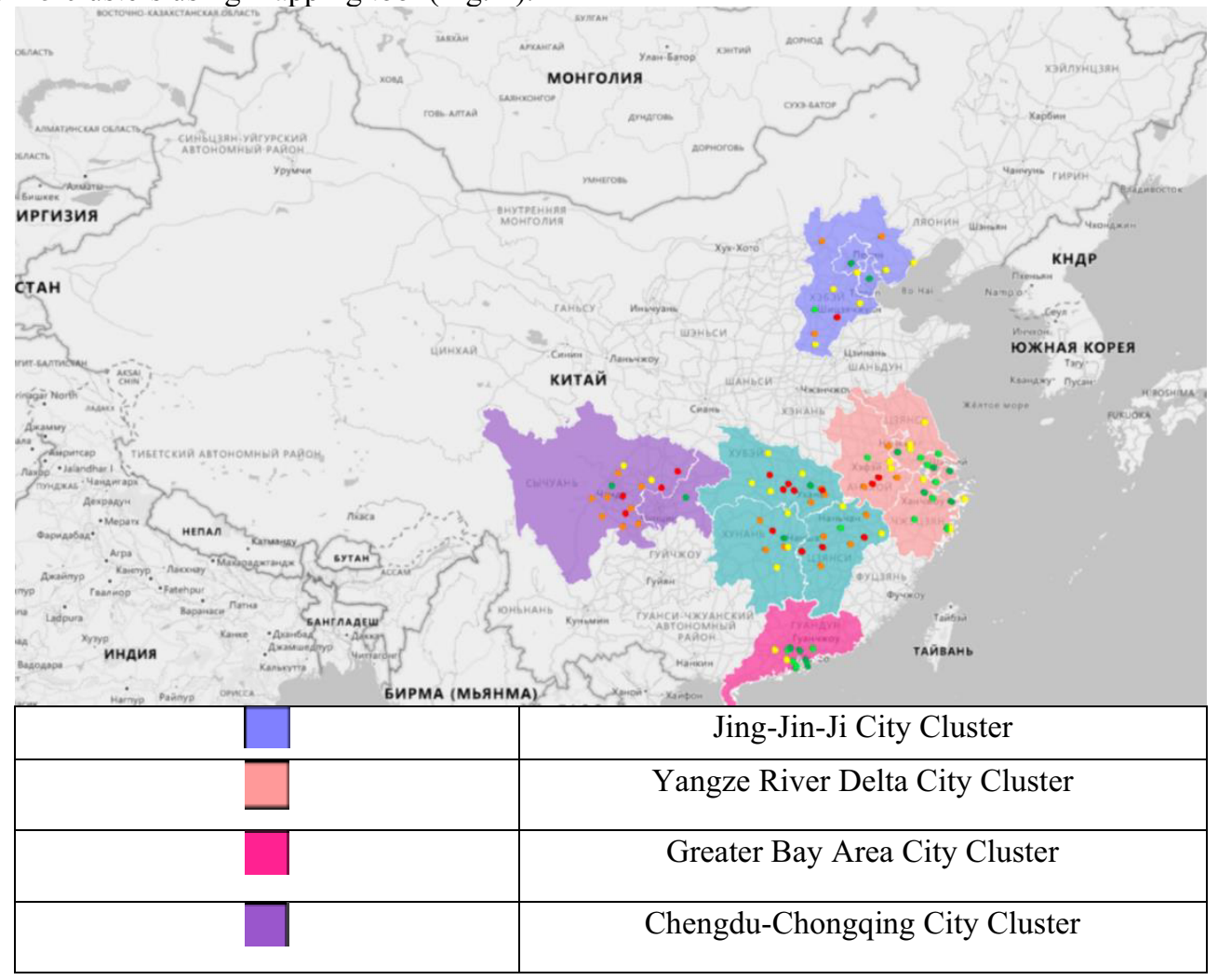




\begin{tabular}{|c|c|}
\hline & Middle Reaches of Yangtze River City Cluster \\
\hline$C_{1}(2$ & Smart city range \\
\hline
\end{tabular}

Figure 2. Five key smart city clusters in China

Source: Compiled by the authors. Data collected from: IDC (2020), USCC (2019), PWCC (2020), OAV (2019).

On Fig 4, each of the 5 clusters has its color designation, and the color indicator of cities depends on their range (from 1 to 5). We can see that the greatest concentration of smart cities is observed in the cluster Middle Reaches of Yangtze River and Yangze River Delta, but their cities have qualitative differences, in the first, cities of the 4th and fifth ranges prevail, and in the second clusters, first and second ranges. Also, after analyzing the visual element, we noticed that the Greater Bay Area cluster is the undisputed leader in the quality of cities in it, since 5 out of 11 of its cities are representatives of the 1st range, and four cities are of the 2nd range. Another notable feature is that key super-city clusters are concentrated in Southeast China along the Yangtze River.

It is no coincidence that the government plans and promotes cluster development. Thus, it supports urbanization in the country, the growth rate of which, in turn, directly correlates with economic growth. Since residents of cities with higher incomes consume more than rural residents, clustering also increases productivity and investment activity by grouping many companies and increasing the labor market.

Another advantage is that integration into clusters of developed centers and less developed provinces (as in the case of the Jing-Jin-Ji City Cluster, which includes two major cities Beijing and Tianjin and the less developed Hebei province), is helping to reallocate resources. As a result, less developed provincial cities, which are in the early stages of industrialization, move up the value chain and abandon heavy industries that pollute the environment. At the same time, developed centers also move up the chain and concentrate their activities on innovative industries.

However, the priorities in this development are placed in the direction of 3 main clusters: Jing-Jin-Ji City Cluster, Yangze River Delta City Cluster, Greater Bay Area City Cluster. These regions are the most innovative and competitive at the international. Subsequently, the Chengdu-Chongqing City Cluster and Middle Reaches of Yangtze River City Cluster are expected to join them, with the remaining 14 clusters having a less economic impact.

If we talk about the openness of the economies of the three main clusters, then it is the Greater Bay Area City Cluster that is considered the most open region of the country. Since there is the most significant foreign investment as a percentage of GDP, which is due to the internationalism of investment activities in Hong Kong and Macau, with the exclusion of which this indicator reaches the level of the other two clusters. Also, all three main clusters have several free trade zones.

An equally important indicator of the development of a cluster is its transport infrastructure. After examining information on the number of international airports in these three clusters, ports, and data on the development of domestic rail networks, we were able to draw several conclusions. So in the Yangze River Delta City Cluster, there are nine international airports, two ports, and the most extended intercity rail network $(997 \mathrm{~km})$, in the Greater Bay Area City Cluster - 4 airports, three ports, and a $326 \mathrm{~km}$ long intercity rail network, and in Jing-Jin -Ji City Cluster - respectively three airports, one port and longdistance networks $115 \mathrm{~km}$ long. Based on this, the most developed transport infrastructure is observed in the Yangze River Delta City Cluster.

Also, each of the three clusters has cities that stand out for their specific competitive advantages. For example, in the Yangtze River Delta City Cluster, Shanghai has a high 
international presence, as it houses many headquarters of various TNCs, Nanjing is the leading research and educational base, Hangzhou is home to such Chinese giants as Alibaba and Geely. Most of the manufacturing facilities of various technologies are in Suzhou. In Greater Bay Area City Cluster, Shenzhen is characterized by a developed and dynamic entrepreneurial ecosystem and a favorable climate for startups, which has led to it filing the most patent applications in China, and Shenzhen is also home to innovative companies such as BYD, Tencent and Huawei. In the Jing-Jin-Ji City Cluster, Beijing, as the country's capital, acts as a government center. It also has the most substantial research base in China, as many of its best universities are located there. Thus, each of the 3 clusters has its strengths and weaknesses. However, overall, the Yangze River Delta City Cluster is the most developed in most cases, followed by Greater Bay Area City and Jing-Jin-Ji City Cluster. Of course, all of them will have to further overall development and improvement to solve the remaining pressing issues and be competitive in the world arena of super-clusters (Table 3 ).

Table 3. Comparison of five smart city clusters in China

\begin{tabular}{|c|c|c|c|c|c|}
\hline & $\begin{array}{c}\text { Jing-Jin-Ji } \\
\text { City } \\
\text { Cluster }\end{array}$ & $\begin{array}{c}\text { Yangze } \\
\text { River } \\
\text { Delta City } \\
\text { Cluster }\end{array}$ & $\begin{array}{c}\text { Greater Bay } \\
\text { Area City } \\
\text { Cluster }\end{array}$ & $\begin{array}{c}\text { Chengdu- } \\
\text { Chongqing } \\
\text { City } \\
\text { Cluster }\end{array}$ & $\begin{array}{c}\text { Middle } \\
\text { Reaches of } \\
\text { Yangtze } \\
\text { River City } \\
\text { Cluster } \\
\end{array}$ \\
\hline $\begin{array}{l}\text { Number of } \\
\text { smart } \\
\text { cities }\end{array}$ & 13 & 26 & 11 & 16 & 31 \\
\hline Range 1 & 2 & 5 & 5 & 2 & 2 \\
\hline Range 2 & 1 & 8 & 4 & - & 1 \\
\hline Range 3 & 6 & 8 & 2 & 2 & 9 \\
\hline Range 4 & 3 & 3 & - & 8 & 9 \\
\hline Range 5 & 1 & 2 & - & 4 & 9 \\
\hline $\begin{array}{l}\text { Population } \\
\text { (million } \\
\text { people) }\end{array}$ & 111 & 150 & 66 & 91 & 121 \\
\hline $\begin{array}{l}\text { GDP } \\
\text { (billion } \\
\text { yuan) }\end{array}$ & 6,7 & 12,7 & 9,2 & 3,8 & 6 \\
\hline Key issues & $\begin{array}{l}\text { Air pollution } \\
\text { Population } \\
\text { density } \\
\text { Transport } \\
\text { networks }\end{array}$ & $\begin{array}{l}\text { Energy } \\
\text { Aging } \\
\text { population } \\
\text { Cluster } \\
\text { integration } \\
\end{array}$ & $\begin{array}{l}\text { Environment } \\
\text { Smart } \\
\text { manufacturing }\end{array}$ & $\begin{array}{l}\text { Traffic } \\
\text { Natural } \\
\text { disasters }\end{array}$ & $\begin{array}{l}\text { External } \\
\text { migration } \\
\text { Pollution } \\
\text { Transport }\end{array}$ \\
\hline
\end{tabular}

Source: Compiled by the authors. Data collected from: IDC (2020), USCC (2019), PWCC (2020), OAV (2019).

\section{Discussion and Conclusion}

China is actively exporting its smart cities services globally. The Chinese government allocates significant funds domestically to the development of surveillance technologies, egovernment, big data, $5 \mathrm{G}$, and others. The natural result of these investments is the export of these technologies abroad. Realizing such strategic opportunities, some companies, such as Huawei and ZTE, have already opened several dozen research centers in cities in Central America, Europe, Africa, and the Middle East. Therefore, we must assess the contribution of Chinese companies to the construction of smart cities around the world. 
Today there are currently two leading exporters of AI technologies in the global market of smart cities, which are used in many smart cities' solutions related to various observations and monitoring - the United States and China.

We can see that Chinese companies have sold AI surveillance technology to a much more comprehensive range of countries than the United States, namely 63 countries. This is also because developing countries bought many projects on credit, such as Kenya, Laos, Mongolia, Uganda, and Uzbekistan. The American presence is recorded in 32 countries (USCC, 2019).

Another way China is moving in this area is through its active participation in international standardization bodies for the concept of smart cities, such as ITU (International Telecommunication Union), 3GPP (a consortium that develops specifications for mobile telephony), and IEEE (Institute of Electrical Engineers and electronics). Through this participation, China is guiding the standard-setting process in a direction beneficial to its companies.

If we talk about the overall contribution of China to global smart cities projects, then it is not so easy to quantify due to the lack of a single statistical database, incomplete data, or their unavailability. And it will be the aim of the following research project.

The analysis carried out within this article allowed us to conclude that the concept of smart cities is a relevant topic for all countries of the world, which helps to solve many issues on optimizing urban management and has a positive effect on the economic component of the state. Also, we identified features and trends of the world market of smart cities and singled out a leading country in this area, namely China.

The Chinese smart cities market also has the developmental characteristics that have allowed it to succeed. In more detail in this article, we focused on the cluster development and the geography of the smart cities' distribution in China and their strengths and weaknesses in each area. The global smart city market is growing annually. However, now, the concept is not yet at the peak of its development and has not yet shown the world all its power and possible beneficial effects. All this testifies that in current conditions, the inclusion of an increasing number of cities within smart cities is simply inevitable.

\section{References}

1. United Nations, Department of Economic and Social Affairs, Population Division (2018). The World's Cities in 2018 - Data Booklet (ST/ESA/ SER.A/417).

2. Trettin, C., Lăzăroiu, G., Grecu, I., \& Grecu, G. (2019). The social sustainability of citizen-centered urban governance networks: sensor-based big data applications and realtime decision-making. Geopolitics, History and International Relations, 11(2), 27-33.

3. Brundtland, G. H., \& Khalid, M. (1987). Our common future. Oxford University Press, Oxford, GB.

4. Albino, V., Berardi, U., \& Dangelico, R. M. (2015). Smart cities: Definitions, dimensions, performance, and initiatives. Journal of urban technology, 22(1), 3-21.

5. Trindade, E. P., Hinnig, M. P. F., Moreira da Costa, E., Marques, J. S., Bastos, R. C., \& Yigitcanlar, T. (2017). Sustainable development of smart cities: A systematic review of the literature. Journal of Open Innovation: Technology, Market, and Complexity, 3(3), 11.

6. Talari, S., Shafie-Khah, M., Siano, P., Loia, V., Tommasetti, A., \& Catalão, J. P. (2017). A review of smart cities based on the internet of things concept. Energies, 10(4), 421

7. Oliveira, T. A., Gabrich, Y. B., Ramalhinho, H., Oliver, M., Cohen, M. W., Ochi, L. S., \& Coelho, V. N. (2020). Mobility, citizens, innovation, and technology in digital and smart cities. Future Internet, 12(2), 22. 
8. Sun, J., Yan, J., \& Zhang, K. Z. (2016). Blockchain-based sharing services: What blockchain technology can contribute to smart cities. Financial Innovation, 2(1), 1-9.

9. Kumar, T. V. (Ed.). (2019). Smart environment for smart cities. Springer.

10. Pacheco Rocha, N., Dias, A., Santinha, G., Rodrigues, M., Queirós, A., \& Rodrigues, C. (2019). Smart cities and healthcare: A systematic review. Technologies, 7(3), 58.

11. Yun, Y., \& Lee, M. (2019). Smart city 4.0 from the perspective of open innovation. Journal of Open Innovation: Technology, Market, and Complexity, 5(4), 92.

12. Kuecker, G. D., \& Hartley, K. (2020). How smart cities became the urban norm: Power and knowledge in New Songdo City. Annals of the American association of Geographers, 110(2), 516-524.

13. Worldwide Smart Cities Spending Guide. (2020). International Data Corporation (IDC). https://www.idc.com/tracker/showproductinfo.jsp?containerId=IDC P37477 (Accessed: 30 June 2021).

14. Yu, W., \& Xu, C. (2018). Developing smart cities in China: An empirical analysis. International Journal of Public Administration in the Digital Age (IJPADA), 5(3), 76-91.

15. Zhang, N., Nunes, M. B., Peng, G., \& Wang, L. (2019). Lessons learned from the preparation for the $13^{\text {th }}$ five-year plan for large and complex smart cities in China. IADIS International Journal on Computer Science \& Information Systems, 14(2).

16. Reshetnikova, M. S. (2021). Will China Win the AI Race? In Modern Global Economic System: Evolutional Development vs. Revolutionary Leap 11 (pp. 2064-2074). Springer International Publishing.

17. Song, T., Cai, J., Chahine, T., \& Li, L. (2021). Towards smart cities by Internet of Things (IoT) - a silent revolution in China. Journal of the Knowledge Economy, 12(2), 1-17.

18. Wang, M., Zhou, T., \& Wang, D. (2020). Tracking the evolution processes of smart cities in China by assessing performance and efficiency. Technology in Society, 63.

19. Research Report on China's Smart Cities Development. (2019). U.S. China Economic and Security Commission. https://www.uscc.gov/sites/default/files/202004/China_Smart_Cities_Development.pdf (Accessed: 30 June 2021).

20. Wang, L., Jia, F., Chen, L., Xu, Q., \& Lin, X. (2021). Exploring the dependence structure among Chinese firms in the 5G industry. Industrial Management \& Data Systems, 121(2), 409-435.

21. Chinese cities of opportunity 2020. (2020). Price Water House Coopers China (PWCC). Available at: https://www.pwccn.com/en/research-and-insights/chinese-cities-ofopportunities-2020-report.pdf (Accessed: 30 June 2021).

22. China's Urban Future. (2019). German Asia-Pacific Business Association (OAV). Available

at: https://www.oav.de/fileadmin/user_upload/Chinas_Urban_Future_web.pdf (Accessed: 30 June 2021) 